\title{
Mapas de interseções na educação em visualidades: Evento artístico como pedagogia
}

\section{BELIDSON DIAS \\ TATIANA FERNÁNDEZ}

\section{Resumo}

Este artigo explora o evento artístico como pedagógico na Educação em Visualidade. Se situa no encontro entre a virada da visualidade na educação e a virada pedagógica na arte. Tendo como base a Pedagogia Cultural procura abranger como e em que condições o evento artístico pode ser ao mesmo tempo um evento pedagógico e de que maneira se instituem os espaços que promovem eventos educacionais como experiências estéticas. Neste artigo apontam-se bases conceituais e metodológicas que permitem distinguir o espaço de interseção entre a arte e a Educação em Visualidade e suas implicações políticas e culturais: Arte Participante, Pedagogia Cultural e as relações entre política e estética. Neste sentido analisa-se o cruzamento de fronteiras tanto na arte como na educação e criam-se possibilidades de entendimento de uma pedagogia de dissenso.
Palavras-chave:

Cultura visual, pedagogia cultural, educação em visualidade, virada da visualidade, virada pedagógica. 


\title{
Maps of intersections in visual educa- tion: artistic event as pedagogy
}

\author{
BELIDSON DIAS \\ TATIANA FERNÁNDEZ
}

\begin{abstract}
This article explores the artistic event as pedagogical in Visual Education. It lies in the encounter between the Pictorial Turn in education and the pedagogical turn in art. Drawing from Cultural Pedagogy it seeks to cover how and under what conditions an event can be both an educational and artistic event at the same and how are instituted the spaces that promote educational events as aesthetic experiences. In this article it was pointed out conceptual and methodological bases for distinguishing the space of intersection between art and Visual Education and its political and cultural implications: Participant Art, Cultural Pedagogy and their relationships among politics and aesthetics. In this sense it analyzes the crossings of frontiers both in art and education and creates possibilities for an understanding of pedagogy of dissent.
\end{abstract}

Keywords: Visual culture, cultural pedagogy, visual education, pictorial turn, pedagogical turn. 


\section{Situando Fronteiras}

As tensões que ocorrem no encontro entre a prática artística e a prática pedagógica contemporâneas não são encontros fortuitos nem inertes. São choques que na última década provocaram atenção redobrada sobre a arte e educação por parte de artistas, educadores e teóricos da arte. Os sintomas mais visíveis são um maior número de publicações, estudos, experiências, seminários, programas de pós-graduação em arte e educação, e instituições artísticas e culturais com programas educativos. A Educação em Visualidade se apresenta neste cenário como um espaço de interseção entre duas grandes mudanças paradigmáticas que se configuram nas transformações sociais do século XXI, a virada da visualidade na educação e a virada pedagógica da arte. Se trata de um choque porque não é um encontro de conciliação, mas também não é um (des) encontro de práticas dicotômicas. É um 'encontro de águas' onde a arte e a educação sofrem mutações ${ }^{1}$. Essas mutações requerem uma aproximação mais cuidadosa sobre o que ocorre nos espaços de interseção, contaminação e hibridação.

A noção de pedagogia do evento ${ }^{2}$, proposta por Dennis Atkinson (2011, 2012), está na raiz do que chamaremos neste estudo de evento pedagógico e se estende por igual à ideia de evento artístico. Ele entende o evento, na linha de Alain Badiou (2002, 2005), como um distúrbio ou uma ruptura na forma de entender e atuar. Assim, um evento está por uma parte relacionado ao novo ${ }^{3}$, mas também ao inesperado, àquilo que não pode ser calculado ou ao indesejável. Um evento, por outra parte, acontece em uma dada situação, mas não pertence a ela já que um evento só se manifesta como uma perturbação que ainda não se compreende. Um evento 
não pode se recortar porque está encadeado a outros eventos. Nesta perspectiva o evento tem o poder de ativar uma aprendizagem real porque sendo algo que perturba uma situação corrente ou interrompe uma repetição conduz a um novo estado ontológico. Desta maneira, tanto o evento pedagógico como o evento artístico são compreendidos como perturbações e rupturas que conduzem ao desconhecido, ao inesperado ou ao novo com novas conexões.

Logo, o argumento central se apoia na ideia de que o evento pedagógico e o evento artístico são eventos culturais e políticos porque participam da dinâmica do poder social de representação e produção de visualidades. Para articular este argumento é necessário questionar o conjunto de suposições que fazem da educação e da arte instrumentos de dominação. Por este motivo não pode ser uma pesquisa politicamente neutra.

Antes de tudo no contexto deste estudo é necessário estabelecer relações ao invés de apontar definições porque não se trata exclusivamente ou principalmente de produzir conhecimento, mas como destaca Graeme Sullivan à respeito da visão dos povos indígenas "o importante é se relacionar com o conhecimento" (2010, p. 172). Por este motivo não podemos considerar que o dever dos educadores e pesquisadores é transmitir um conjunto de conhecimentos e experiências culturais como entidades fixas e préexistentes. O conhecimento é produto de uma negociação na ação comunicativa. Neste sentido o conhecimento per se deixa de ser o objetivo da educação. Saber para quem, para que e em relação ao quê é crucial. Analogamente no estudo da arte é crucial saber para quem, para que e em relação ao quê. Badiou (2005) observa que o conhecimento é o que repetimos e isto não traz nenhuma verdade porque se limita ao que já se sabe, o evento sendo o novo, o imprevisto ou o surpreendente é a verdade. Neste caso ele aponta uma mudança epistemológica sobre a ideia de verdade não mais como mimese: no nosso tempo a ideia de verdade se concebe como relação. A verdade está desta maneira nos eventos que mudam nossa vida. Mas o problema da verdade é sua aparência, ela está sempre em fluxo, por este motivo a verdade deve ser compreendida como um processo na realidade. Assim neste artigo a relação entre o evento pedagógico e o evento artístico é uma relação de potência transformadora porque procura o sentido "para alguém, para algo em relação a outro". 
Uma pedagogia que procura saber "para quem, para que e em relação ao que" que não se funda em dicotomias, mas na complexidade de relações que se estabelecem no fluxo da realidade requer de uma filosofia de associações e relações antes que de distinções (DEWEY, 1929, 2005). Esta forma de filosofia se inscreve naquilo que Walter Mignolo chama de "pensamento de fronteira" porque se situa na tensão das fronteiras/limites/bordas onde se pensa em conceitos dicotômicos antes que no ordenamento do mundo em dicotomias (MIGNOLO, 2012). Mignolo localiza este pensamento de fronteira nos limites do sistema moderno/colonial que para ele são dois lados da mesma moeda. A colonização é constitutiva da modernidade, argumenta ele, e o percurso desta história é um percurso que deve ser pensado nas suas dicotomias. Um pensamento de fronteira é capaz então de se articular e relacionar nos espaços em que as coisas são uma $e$ outra, não uma ou outra.

A Pedagogia Cultural articulada por Henry Giroux como uma pedagogia de fronteira (TREND, 1992; WEINER, 2001; GIROUX, 2005, 2012) vê a prática educativa como uma forma de produção política e cultural que responde às preocupações contemporâneas implicadas na visão ampliada do papel da arte na educação que vive na tensão com as manifestações, produtos e fenômenos da cultura visual. No âmbito acadêmico Giroux reúne duas linhas de estudo independentes, os estudos culturais e a pedagoga crítica, que convergiram nas últimas duas décadas no interesse pela práxis transformadora que indaga sobre as relações entre poder e conhecimento e pelo esforço em relacionar as teorias e práticas pedagógicas à produção cultural (WEINER, 2001). A este interesse político pela relação entre cultura e educação se somam os recentes estudos da cultura visual, feministas, pós-coloniais, de mídia, pós-estruturalistas e da teoria queer. Essas propostas provocam perturbações que remapeiam as relações entre arte, educação e política. Uma Pedagogia Cultural se insere nesta perspectiva, como aquela que se dá na tensão das fronteiras e que mantém uma dinâmica fluida com a cultura. Ao final, se trata de compreender a pedagogia como uma forma de produção cultural e a produção cultural como uma forma de pedagogia.

Uma abordagem cultural e política da arte na educação reivindica uma epistemologia que aborde outros artefatos, processos, eventos e fenômenos da visualidade por dois motivos: por uma parte a arte não autosuficiente para 
compreender a sua dinâmica e ela nem sempre é autorreferencial, pois de alguma maneira sempre estabelece relações "entre". Por outra parte não é uma simples inclusão de outras visualidades além da arte na mesma estrutura curricular e metodológica dos sistemas educativos, é antes uma ruptura com estas estruturas para instituir práticas curriculares e metodológicas que se atrevam a traspassar fronteiras inscritas na cultura, na sociedade, na história, na psique, no corpo e no espaço (GIROUX, 2005, 2012) como se propõem as pedagogias de fronteiras. Este artigo procura explorar o lugar de cruzamento entre as visualidades, a educação e a política onde é possível criar aquilo que Felix Guattari chama de "uma revolução molecular" (1996, p. 161) porque provoca, como veremos, rachaduras na ordem das coisas que levam a transformações. Num contexto em que a arte é só uma parte da visualidade cultural esta pesquisa se adere assim à nomenclatura de Educação em Visualidade para se referir ao que Belidson Dias (2011, 2012) chama de campo ampliado da Educação em Artes Visuais. Desta maneira as bases epistemológicas deste artigo se encontram na Pedagogia Cultural.

\section{As visualidades}

Hoje nos encontramos no tempo da virada da visualidade, dos questionamentos sobre o olhar, os fenômenos de vigilância óptica, a visualização do conflito e seu papel nas relações entre poder e emancipação (MITCHELL, 1995, 2005; FOUCAULT, 2008), das interfaces visuais nas tarefas diárias, de maiores demandas de conhecimentos que se articulam ao redor dos fenômenos da imagem e da visualidade. Por outra parte o inerente caráter político das imagens e das visualidades (RANCIÈRE, 2005, 2007; MITCHELL, 2005) apontam a necessidade de reinventar práticas sociais e institucionais como a educação, capazes de responder ao paradigma ético -estético que se configura na complexidade do nosso tempo (GUATTARI, 1996).

Como uma recente historiografia tem nos ensinado, a visualidade se converteu em um espaço de significação que confere ao ser humano maior poder de agência e transformação, maior até do que a língua. A condição viral da fotografia e do vídeo nas redes sociais, por exemplo, não encontra o limite imposto pela língua. A facilidade para capturar imagens e manipulá-las com interfaces visuais populariza a 
criação imagética e oferece com isto um espaço de ruptura e emancipação que é o espaço da subjetivação. A experiência estética da arte pode ser transformadora, mas não é a única que tem este poder. Por exemplo, o evento de "11 de setembro" não é arte, mas constitui uma experiência estética que marca a visualidade do nosso tempo. A arte é uma parte importante da visualidade cultural e mantém uma relação de conservação, tensão e transformação que mantém a cultura viva, mas existem muitas outras forças visuais que entraram em jogo na contemporaneidade.

Este domínio da visualidade que W.J.T. Mitchell (1995) cunhou de pictorial turn aqui se traduz como virada da visualidade (ou virada imagética) no qual a palavra picture se refere a todos os meios que são suportes de uma imagem e se traduzem como objetos de visualidades. A visualidade emerge como um paradigma nas discussões centrais e críticas das ciências humanas, mas para Mitchell a preocupação cada vez maior para defender a centralidade do discurso frente à visualidade é um dos sinais mais claros de que existe uma virada da visualidade. Hoje o pós-estruturalismo, os movimentos feministas, os estudos pós-coloniais, a teoria queer e os estudos da cultura visual aprofundam as reflexões em torno da virada da visualidade como uma mudança nas relações de poder. Esta mudança por sua vez afeta a maneira como construímos o conhecimento e isto significa que deve haver uma mudança nas formas de aprender e ensinar. O que está em jogo é a ressignificação e reapropriação da subjetividade para uma emancipação do pensamento dominado (RODRIGUEZ, 2008; RANCIERE, 2002).

No contexto de uma procura por coincidências entre o evento artístico e o evento pedagógico a noção de virada da visualidade oferece uma maior incidência crítica sobre os fenômenos culturais e artísticos na sociedade porque reflete tanto sobre a imagem como a mídia e não separa o evento do espectador e do contexto. No momento que a arte perde a sua aura sagrada com a reprodutibilidade técnica da imagem e passa a se fundar na práxis política as exigências são tão grandes como a própria emancipação. A modernidade viveu com isso o dilema do fim da arte. Mas quando entramos no domínio da visualidade as fronteiras que se estabeleceram entre arte e vida se pervertem, se contaminam e se permeiam.

Nas últimas décadas a crescente transculturalização (ORTIZ, 1983) contamina ainda mais a noção monolítica e 
hegemônica da arte e amplia seu entendimento a uma prática autopoética ou de reconstrução do ser individual e social. Mas estas transformações não são homogêneas nem instantâneas e afetam de modos diversos as diferentes sociedades e suas práticas estéticas. A instabilidade conceitual é inerente à arte por muito que possamos incluir nela todas as formas em que é abordada. Não só a sua prática é diversa, mas seu sentido também é amplo, arte é a qualidade do fazer e daquilo que é feito. Se nos atrevemos a procurar algo que seja comum às diversas práticas artísticas poderíamos dizer que a arte é uma forma que as culturas tem de se reconstruir, de estabelecer o que Guattari (1996) chama de "territórios existenciais". Aprender e criar são neste caso junções transversais de um mesmo ato. A arte é, devido à sua intenção estética, uma forma de apreender o mundo mas também de reconstruí-lo.

Humberto Maturana e Fernando Varela (1995) reconhecem, na teoria da autopoiese ${ }^{4}$, esta mesma dinâmica na estrutura dos organismos vivos: vivemos porque aprendemos e nesse processo nos reconstruímos. O que nos caracteriza como humanos, no entanto, é a capacidade de estender este processo autopoético à nossa linguagem no esforço por ressignificar o ato de viver. A arte é nesta visão uma forma de aprendizagem, ou como prefere Dewey, uma forma de crescimento. Sendo assim podemos falar também de uma virada pedagógica da arte.

Na transição entre a modernidade e a pós-modernidade artistas como Joseph Beuys, John Cage e Robert Filliou do grupo Fluxus estabeleceram práticas artísticas que eram ao mesmo tempo práticas pedagógicas e políticas. Da mesma maneira o artista conceitualista uruguaio Luis Camnitzer (2009) vê relações transversais entre arte, educação e política na arte conceitualista da América Latina na obra de Cildo Meirelles, Lygia Clark e Hélio Oiticica, entre outros. Estes artistas questionaram as instituições e o sistema da arte que promoviam visões dicotômicas entre processo e produto, entre objeto e sujeito. O privilégio do artista de ser o único que atribui sentido à obra e às práticas interpretativas modernas que viam o significado contido dentro da obra perde sentido no contexto de uma cultura cada vez mais líquida (BAUMAN, 2006), complexa, espetacular e tecnológica.

Na última década diversos artistas desenvolvem de maneira coletiva e engajada trabalhos que diluem as fronteiras entre arte e educação com obras que ocupam instituições 
educativas ou que se envolvem de maneira relacional com seu público como, por exemplo, Liam Gillick ou Rainer Ganahal, os eventos artísticos que envolvem a comunidade educativa, como o trabalho de Tim Rollins, a Bienal do Mercosul no Brasil ou as escolas de arte concebidas como obra de arte como a escola Cátedra de Arte de Conduta realizada em Cuba por Tania Bruguera. Destacamos também iniciativas educativas que são consideradas eventos de arte como os projetos Academy de Irit Rogoff e Summit nos Paises Baixos, as universidades livres que surgiram em 2001 como a Copenhagen Free University - CFU que procuravam o debate e produção de processos comunitários de conhecimento enfatizando sobre áreas negligenciadas pelas instituições acadêmicas cada vez mais dirigidas ao serviço da indústria corporativista. Estes artistas reconhecem a natureza ideológica do conhecimento e promovem uma pesquisa politizada e socializada que não encontra espaço nas instituições acadêmicas tradicionais.

Nicolas Bourriaud (2009) considera o trabalho de alguns destes artistas como uma estética das interações humanas e seu contexto social que ele chama de "Estética Relacional". Nesta visão a arte acontece no processo de uma interação onde o sentido é dado nas relações que se estabelecem, no diálogo entre o artista e os espectadores, que neste caso se transformam em participantes, coautores ou mesmo autores; construção coletiva antes que privada. Mas é importante observar que, na velocidade das mudanças culturais as relações humanas se tornam mais complexas, diversas e fluídas o que aponta uma maior complexidade nos processos de subjetivação.

Já Claire Bishop (2012) prefere ver estas obras como propostas criativas de participação politizadas que chama de Arte Participante ${ }^{5}$ onde as pessoas constituem o meio artístico e material principal. Nesta perspectiva o artista, aponta Bishop, se concebe como um colaborador e produtor de situações e as obras de arte como projetos em processo sem um começo ou final delimitado e o público um coprodutor ou participante. Nesta tendência Bishop identifica um "retorno ao social da arte" e adverte que para não cair na ambiguidade com que o discurso da arte socialmente engajada pode servir ao programa neoliberal para fortalecer as relações de poder e dominação é necessário acentuar o caráter estético da experiência e sua singularidade. Esta pesquisa se inscreve na visão de Bishop de Arte Participante porque 
não se trata, como é para Bourriaud, de criar espaços de relacionamento (porque retorna à posição de quem dá a quem não é capaz de tomar por si), mas de se relacionar com os participantes como singularidades em construção.

\section{Educação, visualidade e cotidiano}

A fragmentação e hierarquização nas relações de poder na Educação começaram a mudar na década de 1970 sob a influência dos marxismos, feminismos, estudos culturais, pós-estruturalismo e estudos subalternos como o pós-colonialismo e pós-ocidentalismo. São linhas de estudo que se cruzam de várias maneiras. A ideia de um leitor como um coautor do texto $^{6}$ e a interpretação como um percurso aberto conduz à evolução de um discurso complexo no campo da arte e da cultura. Isto significou uma mudança epistemológica no pensamento marxista que vai das preocupações com a luta de classes, a revolução do proletariado, a formação da história e da sociedade e a economia de produção a uma preocupação com as questões de representação, identidade, desejo, tecnologia, poder e linguagem. Este cenário reivindica uma maior preocupação com as relações que o texto estabelece com o público do que nas suas relações formais internas ${ }^{7}$. Na pedagogia, as implicações são críticas, pois a maneira de ver o mundo é a maneira de interpretá-lo. A maneira de ver o mundo se torna uma estratégia e todo conhecimento uma questão de representação e interpretação. Por este motivo as narrativas particulares, ou pequenas narrativas, adquirem uma nova proeminência frente às grandes narrativas modernas. $\mathrm{O}$ que está em jogo nas narrativas particulares é a capacidade de agência, de flexibilidade, de negociação, de abertura e de crítica que permitem quando as histórias particulares contam, quando o poder de fazer se corporifica. Esta abordagem das narrativas particulares é por si mesma conflitante, seja na educação da arte ou de outra disciplina, porque promove uma visão crítica das noções fixas e conservadoras de identidade cultural, conduz os estudantes e os professores a enfrentar assuntos sensíveis sobre religião, raça, gênero, sexualidade e excepcionalidade e por tanto a uma revisão das próprias estruturas mentais.

As narrativas particulares valorizam o cotidiano porque visualizam a maneira em que fomos construídos e em que continuamos a construir em sociedade. A ressignificação do cotidiano na arte se manifesta não só em obras que operam 
com a imagem da intimidade ou com os objetos e seus contextos, mas principalmente naquelas que operam com os espaços de relacionamento e participação humana (BOURRIAUD, 2009; BISHOP, 2006, 2012). As vanguardas modernas já demonstram uma preocupação com a forma como vemos os objetos da vida cotidiana, a arte pop e conceitual também estabeleceram relações estreitas com o mundo dos objetos e das condições de relacionamento humanos. Mas é na arte pós-moderna que a cotidianidade adquire uma atenção relevante.

Ao analisar esta questão, Dias (2012) faz uma distinção entre o cotidiano que é povoado de objetos, imagens e fenômenos diversos e o cotidiano das imagens que denomina cotidiano espetacular em relação às ideias de Guy Debord do espetáculo como uma relação social, histórica e política mediada pela visualidade e às ideias de Garoian e Gaudellius de uma Pedagogia Espetacular (2008, apud DIAS, 2012). Mas não se trata somente, como destaca Dias, de associar arte à vida, nem de fixar o estudo das visualidades num único espaço/tempo: "O cotidiano é em si um espaço/tempo que informa o espetáculo de categorias sociais identitárias na nossa cultura" (Ibidem, p. 68). No contexto pedagógico se trata do imaginário visual e da imagética do cotidiano dos indivíduos, não das imagens, por isso é importante compreender o cotidiano dos estudantes e sua vida como o centro das questões pedagógicas. Aldo Victorio Filho nota que as escolas ainda se mantêm afastadas da realidade e das realizações dos seus atores, que para ele são "criadores de currículos e criadores de acontecimentos estéticos, se não no campo da arte, sempre na cotidianidade de suas vidas" (20o8, p. 3). Para ele o maior desafio que temos os educadores em visualidade é explorar o potencial estético da cotidianidade das culturas infanto-juvenis de maneira a favorecer uma pedagogia voltada para "justiça social e coletivização das belezas" (Ibidem.).

A ênfase sobre o cotidiano desafia a categorização das artes em "altas" ou "belas" e de outro lado "populares" ou "menores" ou inclusive "kitsch" ser desconstruído nas relações entre poder e conhecimento é a arte. O que se critica são os métodos de pesquisa e abordagens da história da arte modernos como construções de poder que excluem por uma parte toda manifestação estética não "ocidental" e por outra depreciam ou ignoram a dimensão estética da cultura popular, da cultura de massa, do artesanato e do de- 
sign e sua intrincada relação com as manifestações artísticas legitimadas pela cultura dominante do Ocidente.

\section{Culturalismos: poder, diversidade e pedagogia}

Nesta seção, o nosso argumento segue a linha foucaultiana ao proporcionar as bases filosóficas para uma revisão crítica das relações de poder e conhecimento que são construídas e mantidas através do discurso social, mas que também estão estreitamente relacionadas com as formas do olhar, as formas de representação e de vigilância visual. Como argumenta Mirzoeff (2009) "a visualidade é aquilo que faz visível o processo da Historia para o poder" (Idem, p.5), "a visualidade visualiza o conflito" (Idem, p.6), na linha do pensamento foucaultiano o princípio do poder é o poder da visibilidade.

As relações entre poder e conhecimento apontam as questões sobre diversidade e diferença nas teorias feministas. É compreensível que Jana Sawicki (1991) sugira, em base ao pensamento foucaultiano ter em mente que o poder é exercitado, não possuído; é produtivo, não repressivo; é distribuído, não comprimido desde cima de tal maneira que seja aceito o pluralismo, a convivência democrática, o respeito pelas múltiplas perspectivas enfrentando o conflito e integrando conhecimentos e saberes diversos e diferentes. Os questionamentos sobre quem define a identidade, quais as relações de poder que influenciam sobre ela, a normalização e o biopoder (ver BUTLER, 2004; SAWICKI, 1991) são semelhantes aos que emergiram dos movimentos raciais e os estudos pós-coloniais.

Do ponto de vista mais crítico, os teóricos atuais, que argumentam por políticas da diferença, têm posições múltiplas e às vezes até contrárias sobre o multiculturalismo. Inicialmente quando era sobre "pluralismo cultural" estas diferenças de posição existiam entre os chamados assimilacionistas e os pluralistas, os assimilacionistas queriam integrar o outro na própria cultura e os pluralistas defendiam a necessidade de manter a integralidade das diferenças. Esta é também uma diferença entre o conceito de tolerância e o de convivência cultural. A tolerância é sempre transitória e condicional, implica alguém que tolera e um outro que é tolerado. Os assimilacionistas toleram por meio de uma abordagem étnica que representa o outro como distante, "mantendo as questões sobre relações de poder na sociedade à distância" (CAHAN e KOCUR, 1996, p. xxi). Esta é também 
a distinção entre diversidade e diferença. A diversidade, como explica Richard Miskolci (2012, p. 47), é "cada um no seu quadrado", todos convivem e se toleram, mas a cultura continua sendo o que ela é. As políticas da diferença põem acento na especificidade e na pluralidade, no "inesperado, o criativo, o novo, o que realmente pode mudar a ordem do poder" (MISKOLCI, 2012, p. 49). A proposta de quirização ou transviar9 (DIAS, 2011) da educação aponta à valorização da diferença que compreende não só as diferenças de gênero, mas também as questões de sexualidade, raça, religião, excepcionalidade e colonização.

E dentro desta perspectiva que se enquadra o fato de artistas contemporâneos aderirem às "políticas da diferença" ao buscar desafiar as noções monolíticas e hegemônicas da História da Arte por meio de uma prática do múltiplo e do heterogêneo que rejeita um discurso universal, genérico e abstrato e valoriza realidades particulares, específicas e concretas (WEST, 1990, apud CAHAN e KOCUR, 1996). $\mathrm{Na}$ arte, as questões sobre o como e o que é diferente adquirem centralidade. As referências ao sincretismo religioso, as narrativas autobiográficas, a complexidade da identidade e o poder da autorrepresentação são materiais para uma "educação interdisciplinar em que a arte se entende tanto como produto da história como agente de mudança social" (CAHAN e KOCUR, 1996, p. xxiii).

É compreensível que Camnitzer (2009) observe que o mesmo fenômeno acontece com a noção de multiculturalismo no âmbito da arte. Apesar da intenção antihegemônica desta ideia há uma deterioração considerável na prática artística. O multiculturalismo se torna uma ferramenta de apropriação das manifestações periféricas consideradas úteis e assim as políticas governamentais e coorporativas de maneira global neutralizam as expressões de dissenso das subculturas categorizando-as como exóticas e tornando-as grife para explorar no mercado. Na última década os artistas da periferia não querem mais ser reconhecidos pelo exotismo da sua "outridade" mas pela especificidade da sua prática artística para evitar a antropologização do seu trabalho sem que isto signifique uma submissão às regras do mercado internacional. Tudo isto nos leva a pensar que se torna cada vez mais crucial uma pedagogia do dissenso que permita a visibilidade da singularidade na pluralidade para que as estratégias que neutralizam a cultura e a arte sofram sempre um processo de visualização. 
Por outra parte, devemos tomar em conta que a multiculturalidade é uma noção que surge no mundo anglo-saxão e se refere aos esforços para uma convivência pacífica entre diversas culturas constituídas pelos imigrantes que conservam seus modos de vida. Na América Central e do Sul os colonizadores, os colonizados, os escravizados e os imigrantes formaram uma intrincada rede de relações culturais híbridas porque se misturaram. Isto não significa que a hibridação é isenta de conflito, mas criou uma subjetividade "camaleão" que é capaz de mudar segundo o contexto. É muito comum nas nossas sociedades latino-americanas a capacidade das pessoas fluírem entre diversas culturas, estratos sociais, raças, comunidades, linguagens ou gêneros sem maiores dificuldades. Neste contexto as culturas não se conservam. A mudança é, além do mais, recíproca: todos mudam. Todos tem algo de colonizador e colonizado ao mesmo tempo. Talvez seja por isso que os exemplos dados nos levem a concluir que é necessário ir além do multiculturalismo e pensar num transculturalismo.

O transculturalismo, como aponta Gerardo Mosquera (CONFERÊNCIA GERARDO MOSQUERA, 2009), faz ênfase sobre a vocação antropofágica de devorar a cultura dominante como forma de resistência. O termo, proposto por Fernando Ortiz (1983) para tratar do intercâmbio e apropriação cultural pela cultura subalterna, propõe uma estratégia cultural consciente da sua capacidade de afetar e ser afetado pelo "outro". A apropriação não é um processo novo na formação das culturas, mas é crítico em condições de dominação cultural como no caso latino-americano, pois é necessário reavaliar constantemente até que ponto a apropriação da cultura dominante torna os antropófagos seus consumidores facilitando os propósitos de dominação.

Torna-se evidente que é importante ocupar os "entre -lugares" também chamados por Homi Bhabha (1997) de "Terceiro Espaço" onde as culturas se encontram de diversas maneiras. Estes são espaços de dissenso, por tanto espaços de criação que não são necessariamente parte dos espaços culturais instituídos nem parte da hibridação cultural do contexto. Em outras palavras a transculturalidade considera elementos que não se dissolvem, que se querem diferentes, que resistem mesmo à hibridação, que produzem novas subjetivações fora das culturas em criação. Néstor García Canclini pensa que a hibridação "não é sinônimo de fusão sem contradição" (2001, p. II). O "Terceiro Espaço" é o 
espaço da contradição e por tanto o espaço da "conversação complicada". Daniel Trend (1992) observa que pesquisas dos estudos culturais na década de 1990 mostram que os mecanismos sociais nunca estão completos, sempre se formam resistências, rejeições, ou reconfigurações em subculturas, como as dos adolescentes.

Os resultados disso são bastante generalizados, a Pedagogia Cultural irá propor esta relação entre pedagogia crítica e produção cultural como um projeto político e ético (GIROUX, In TREND, 1992). Desta maneira ela é inseparável de democracia cultural ou "democracia radical" como a chama Giroux (Idem, p. viii). A Pedagogia Cultural proporciona as bases para compreender a identidade do professor como um "trabalhador cultural" e a educação como uma produção cultural. Esta posição retoma muitos dos princípios da filosofia da educação reconstrucionista social (DEWEY, 1920) que ressurge em épocas de crises no século XX e hoje se torna adequada à contemporaneidade, em que as mudanças são velozes e as crises são profundas. Mas a transformação e o reajuste podem ser interpretados de muitas formas, o que conduz ao questionamento fundamental de quem determina o que, como e para que deva se transformar, reconstruir ou se reajustar uma sociedade.

Esta é outra razão pela qual a escola deve ser compreendida como geradora de cultura, como defende Fernando Hernández. Ele considera a sala de aula como um cenário que tem uma cultura própria, mas não única, que vai se definindo "mediante as diferentes formas do discurso que se desenvolvem e se encenam nas situações de aula". (HERNÁNDEZ, 1998, p. 32). Nesse contexto os processos de ensino-aprendizagem não giram em torno a normas, regularizações ou disciplinarização, mas sobre as complexas relações entre subjetividades, interesses, situações e contextos sociais e culturais e experiências de vida. Sobre a incerteza que envolve a ação pedagógica e a necessidade de correr o risco de trabalhar na dimensão da complexidade das relações e das incertezas Atkinson argumenta que "uma aprendizagem real envolve um movimento a um novo estado ontológico", por tanto "aprender pode se entender como um problema de existência” (ATKINSON, 2008, p. 10).

Em última análise, como Atkinson, Hernández (1998) defende a necessidade de reconhecer a complexidade das situações e a sua singularidade. Isto significa para ele uma escola que privilegie a perspectiva relacional do saber que supõe ensinar 
a questionar toda forma de pensamento único, reconhecer as concepções que o regem, incorporar uma visão crítica que pergunte quem se beneficia e quem se marginaliza nisto, introduzir visões diferenciadas que evidenciem que o saber se constrói desde pontos diferentes e as tensões de poder que existem entre estas diferenças para legitimar sua visão de mundo e observar que toda realidade responde a uma interpretação e que esta interpretação tem geralmente um interesse ligado à hegemonia de determinados grupos.

Haja vista os comentários que fizemos, é evidente que Giroux (2005) se refere nestes termos a uma "pedagogia de fronteira" e Atkinson $(2008,2011)$ a uma "pedagogia contra o estado" e a "uma pedagogia do evento". Ambos se referem a uma pedagogia que além de crítica é agenciadora de transformações, geradora de um "novo estado das coisas". A Pedagogia Cultural é, pois uma pedagogia de fronteira, uma pedagogia contra o estado e uma pedagogia do evento, porque se trata de cruzar fronteiras e de proporcionar condições para que os estudantes sejam "cruzadores de fronteiras", para que vivam conversações complicadas e experiências estéticas, para que se criem territórios de existência e de dissidência como compreendida por Rancière (2010) para quem a dissidência é o coração da política e o consenso a política reduzida ao ato autoritário da polícia.

\section{Experiência estética e evento}

Uma diferença que separa Dewey dos teóricos que influenciaram a estética moderna do século XIX é sua crítica à estética do desinteress $\mathrm{e}^{10}$, que chamou de "ideia esotérica da arte" (DEWEY, 2005, p. 87) porque proclama uma autonomia respeito à funcionalidade da arte na vida colocando as discussões estéticas e artísticas no exclusivo domínio das elites culturais e longe da vida e das classes empobrecidas e dominadas. Esta visão redutora da arte às "artes maiores" ou "belas artes" reflete e reforça a divisão entre pensamento estético e trabalho prático que é por sua vez uma divisão entre classes sociais, mas também entre meios e fins, entre espaço e tempo, e entre objeto e sujeito da arte. A indivisibilidade e a intercambiabilidade entre teoria e prática, meios e fins, espaço e tempo, sujeito e objeto, matéria e forma são para Dewey a substância comum das artes. A cor pode ser o meio como pode ser o fim, ou mesmo meio e fim; o tempo e o espaço na experiência se qualificam um a outro em um mesmo efeito, sujeito e objeto se tornam um na 
experiência estética, matéria e forma se transferem valores de acordo a direção dos nossos interesses: "[os significados] não são acrescentados só por associação, mas são igualmente a alma da qual as cores são o corpo ou o corpo do qual as cores são a alma- de acordo a nossa preocupação com a imagem" (DEWEY, 2005, p. 123, grifo nosso). Nestas bases é possível encontrar experiência estética tanto nas coisas úteis como nas ociosas, tanto na arte como no artesanato, no design ou na poesia, na ciência ou na vida cotidiana.

Sendo a arte um evento culminante da experiência humana, "a arte faz os homens se darem conta da sua união em origem e destino" (DEWEY, 2005, p. 282). Dewey propõe traspassar assim as fronteiras entre o sujeito e o objeto compreendendo a experiência estética como um encontro em que objeto e sujeito se completam e isto se estende ao encontro entre sujeitos. Da mesma maneira que para artistas e teóricos contemporâneos, para Dewey a própria experiência estética é uma criação onde tanto o artista como o espectador trabalham sobre a obra criando sua própria experiência. Esta criação se trata de um ordenamento, reordenamento ou recriação dos elementos do todo que compõe a forma. "Em toda experiência integral", argumenta Dewey, "há forma porque há uma organização dinâmica. Chamo dinâmica a organização porque leva tempo para se completar, porque é um crescimento." (2005, p. 57). Em efeito, para Dewey a forma só se completa se há uma progressiva construção de valores, uma cumulativa conservação de experiências que é ao mesmo tempo uma preparação para o suspense, a antecipação do que ainda vai ser vivido. Fazem parte desta forma as tensões que criam resistência na adaptação das partes, na sua interpretação, construção ou reconstrução. Por esta razão a consumação da forma é relativa, recorrente e fluida. "Continuidade, acumulação, conservação, tensão e antecipação são condições formais das formas estéticas" (Idem, p. 143), afirma Dewey. Esta dinâmica da formação está profundamente enraizada no mundo: na interação do meio ambiente com o organismo no seu crescimento.

Neste sentido as dicotomias entre processo e produto, entre sujeito e objeto, entre artista e espectador não se sustentam. Tudo isto tem implicações para a forma como pensamos a prática pedagógica na Educação em Visualidade. Se a pensamos como uma prática artística, que é situacional porque se refere à acumulação e conservação, que é complexa porque reconhece os conflitos e ressalta as tensões e que é 
imaginativa porque antecipa seu movimento em direção ao desconhecido, teremos uma forma de pesquisa e de construção da experiência estética em estreita relação com a dinâmica orgânica da vida.

$\mathrm{O}$ conceito de experiência estética também responde às preocupações contemporâneas com as noções monolíticas e hegemônicas da arte como uma tradição histórica exclusiva de Ocidente e da estética ocidental como a única filosofia que pode validar a arte. A dicotomia entre os valores internos e os valores externos da arte que se debatem sobre estas noções conduzem a duas vias que são igualmente perniciosas. Se a arte se define exclusivamente pela sua própria prática (valores internos) se converte num argumento circular e se arte se define pela sua aplicabilidade ou utilidade (valores externos) se converte em instrumento para outro fim.

Desta maneira o conceito de experiência estética não pretende nem é adequado como forma de definir ou como base para analisar objetos ou ações artísticas: "A experiência estética não tem sido acreditada para gerar seus próprios conceitos na interpretação da arte. Estes foram superimpostos por meio de pacotes prontos enquadrados em sistemas de pensamento que não fazem referencia à arte" (DEWEY, 2005, p. 136). É por tanto importante notar que a noção de arte como experiência estética não poderia constituir nem substituir qualquer conjunto de critérios para julgar obras que aspiram ser consideradas arte em qualquer tempo ou lugar. Esta abordagem filosófica se centra na experiência humana com os fenômenos estéticos e por tanto considera que os critérios para definir o que é ou quando é arte estão sempre em construção, desconstrução, reconstrução, deslocamento e superposição. A arte faz isto ao mesmo tempo em que se mantém em fluxo na vida em transformação.

A ideia de experiência estética de Dewey é por si mesma uma ideia que pode ser compreendida em face a muitas formas de relacionar arte e vida. $\mathrm{O}$ que interessa neste breve artigo é afinar esta ideia nas condições em que a virada da visualidade e a virada pedagógica se encontram, que são condições diferentes daquela em que Dewey pensou a experiência estética. O conceito de evento pedagógico de Atkinson (2008, 2011), que como argumento se estende ao conceito de evento artístico, se relaciona à experiência estética deweyana na ênfase sobre o corpo em sua experiência com o mundo, isto é sobre a existência. Para ele a ideia de existência implica em um estar (being there) em um lugar particular de tal maneira 
que a diferença permita estabelecer relações, estruturas, posições e identidades entre os seres. Atkinson baseia a ideia de evento na relação que Badiou (2005) estabelece entre "o ser e o evento" como uma transição entre "ser e se tornar", um processo continuo de existência e mudança em que a ruptura, ou o evento, torna visível a subjetividade. Nesta perspectiva é possível pensar que "a aprendizagem real pode ser vista como um problema de existência” (ATKINSON, 2011, p. 39). Como Dewey (2005), ele aponta a potencialidade que a arte tem de romper com as construções fixas da subjetividade para que novas formas de "se tornar" (becoming) possam irromper e se tornar aparentes.

Assim a pedagogia do evento de Atkinson se reconhece como uma "pedagogia contra o estado" porque se propõe como uma ruptura com o estado de coisas. Ele estende a ideia de experiência estética a um plano de vida em tensões extremas e mudanças sociais radicais. Neste aspecto Atkinson reflete sobre os espaços políticos e de dissenso nas situações educativas. Uma pedagogia do evento procura as aberturas que provocam a formação de territórios de subjetivação (GUATTARI, 1996) onde novas formas de entendimento podem emergir. Nesta linha, Atkinson adota a ideia de Rancière de que a democracia não se baseia nos espaços de consenso, que é "reduzir a política ao policiamento" (RANCIÈRE, 2009a) mas nos espaços do dissenso que possibilitam "novas subjetivações e novos caminhos de aprendizagem" (ATKINSON, 2011, p. xi).

Da mesma maneira a ideia de evento artístico se compreende aqui como uma estética que trabalha contra ela mesma, uma antiestética no sentido que não se dá ao luxo de ficar amarrada a modos específicos de prática e a certos valores estéticos. E isto não significa invalidá-los, mas relacioná-los nos fluxos de mudança e subjetivação. O que está por mudar é a ideia de arte e de educação e isto não significa que desaparecem as ideias inscritas pela tradição, mas que se tensionam com outras formas operar. É um movimento que vai da forma a não forma e do conhecimento ao não conhecimento. Este espaço da possibilidade do que "ainda não é" foi compreendido na filosofia de Dewey, mas Atkinson o envolve numa pedagogia do dissenso.

Não por coincidência, Atkinson (2011) observa, como Biesta (2010) e Giroux (2012) entre outros, que o maior obstáculo para pensar a pedagogia do evento são os discursos de auditoria, inspeção e controle que circulam na visão 
tecnocrática da educação porque valorizam práticas de padronização que perpetuam a política do consenso. Isto não acontece no sistema da arte de maneira visível como se dá na educação, mas existem mecanismos neste sistema que, como na educação, funcionam como discursos de validação que perpetuam a ideia de que deve haver um consenso sobre o que é e não é arte. Por este motivo, a ideia de evento artístico não se estabelece numa única posição, seja esta qual for, mas flui entre as diversas formas de entender e fazer arte. Neste aspecto a ideia de experiência estética de Dewey permite se estender nas fronteiras da arte além do consenso: evento artístico como espaço da diferença, do dissenso e daquilo que ainda não é.

Este artigo aponta a hibridação do evento artístico e o evento pedagógico nas bases de uma arte participante onde a escola, sendo um dos espaços mais importantes em que se configuram as relações sociais e culturais, constitui um campo de diálogo coletivo que está em constante negociação, um espaço/tempo social em que é possível explorar uma arte que se proponha a ser dos outros ou com os outros. O seu sentido é uma intervenção radical nos processos sociais em direção à emancipação do pensamento colonizado ou dominado por meio do reconhecimento da diferença que tem consequências importantes sobre como entendemos o conhecimento e por tanto a educação, mas também sobre a noção de arte e a função do artista nas sociedades contemporâneas. Como foi para Dewey, nesta pesquisa a estética e a pedagogia coincidem como uma forma de filosofia e como uma forma de política centrada no corpo e na sua experiência do mundo. Neste aspecto os Estudos da Cultura Visual adquirem uma importância relevante na Educação em Visualidade porque promove uma visão crítica do olhar e da imagem em relação às formas de exercício do poder e do discurso que instituem na arte em outras formas de visualidade e de pedagogias.

\section{Referências}

ATKINSON, Dennis. Pedagogy against the State. JADE. Vol. 27, No. 3, p. 226- 240, 2008.

. Contemporary Art and Art in Education: The New, Emancipation and Truth. iJADE, Vol. 31, No. 1, p. 5 - 18, 2012. ATKINSON, Dennis. Art, Equality and Learning: Pedagogies against the State. Rotterdam: Sense Publishers, 2011. 
BHABHA, Homi. Cultural Diversity and Cultural Differences. In ASHCROFT, Bill; GRIFFITHS, Gareth; TIFFIN, Helen (Eds.). The Post-Colonial Studies Reader. Londondon: Routledge, p. 206-209, 1997.

BADIOU, Alain. Pequeno manual de inestética. São Paulo: estação Liberdade, 2002.

. Being and Event. New York: Continuum 2005.

BAUMAN, Zygmunt. Modernidad Líquida. México: Fondo de Cultura Económica, 2006.

BIESTA, Gert. A New Logic of Emancipation: the methodology of Jacques Rancière. Educational Theory. Vol. 6o, $\mathrm{N}^{\circ}$ 1, p. 39-59, 2010.

BISHOP, Claire (Org.). Participation. Cambridge: MIT Press, Whitechapel Ventures, 2006.

. Artificial Hells: participatory art and the politics of spectatorship. (ebook) London: Verso, 2012.

BOURRIAUD, Nicolas. Estética relacional. São Paulo: Martins, 2009.

BUTLER, Judith. Undoing gender. New York: Routledge, 2004. CAMNITZER, Luis. Didáctica de la Liberación: Arte Conceptualista Latinoamericano. Murcia: CENDEAC, 2009.

CAPRA, Fritjof. O Ponto de Mutação. Pensamento Cultrix, 2001.

CAHAN, Susan, KOCUR, Zoya. Contemporary Art and Multicultural Education. New York: Routledge, 1996.

CONFERÊNCIA GERARDO MOSQUERA. Centro Cultural España Córdoba, 2009. Disponível em: <http:// hipermedula.org/2010/03/gerardo-mosquera-contra-elarte-latinoamericano/>. Acesso em: 14 maio 2013.

DEWEY, John. Reconstruction in Philosophy. New York: Henry Holt and Company, 1920.

. Experience and Nature. London: George Allen \& Unwind, 1929.

. Art as Experience. N.Y.: Penguin Group, [1934] 2005.

DIAS, Belidson. O I/Mundo da Educação em Cultura Visual. Brasília: Editora da Pós-graduação em arte da Universidade de Brasília, 2011.

DIAS, Belidson. Arrastão: o cotidiano espetacular e práticas pedagógicas críticas. In MARTINS, Raimundo; TOURINHO, Irene (orgs.). Culturas das Imagens: desafios para a arte e para a educação. Santa Maria: Editora da UFSM, p. 55-73, 2012.

FOUCAULT, Michael. Vigiar e Punir: nascimento da prisão.

Petrópolis: Vozes, [1977] 2008. 
GARCIA CANCLINI,. Néstor. Culturas Híbridas: Estrategias para entrar y salir de la modernidad. México D.F.: Grijalbo, 2001.

GIROUX, Henry. Border Crossings: Cultural Workers and the Politics of Education. New York: Routledge, 2005.

GIROUX, Henry. Dangerous Pedagogy in the Age of Casino Capitalism and Religious Fundamentalist. Truthout. News Analysis. Wednesday, 29 February, 2012, 05:17. Disponível em: <http://truth-out.org/index.php?option=com_k2\&view=item\&id=6954:dangerous-pedagogy-in-the-age-of-casinocapitalism-and-religious-fundamentalism>. Acesso em: 4 jul. 2012.

GUATTARI, Felix. Caosmosis. Buenos Aires: Ediciones Manantial. 1996.

HERNÁNDEZ, Fernando. Transgressões e Mudança na Educação: Os Projetos de Trabalho. Porto Alegre: Artmed, 1998.

MATURANA, Humberto; VARELA, Fernando G. De Máquinas y Seres Vivos. Autopoiesis: la organización de lo vivo. Santiago. Chile: Editora Universitaria. 1995.

MIGNOLO, Walter. Local Histories/ Global Designs: Coloniaity, Subaltern Knowledges and Border Thinking. NJ: Princeton University Press, 2012.

MIRZOEFF, Nicholas. An Introduction to Visual Culture. New York: Routledge, 2009.

MITCHELL, W.J.T. Picture Theory. London: The University of Chicago Press, 1995.

What do pictures want? London: The University of Chicago Press, 2005.

MISKOLCI, Richard. Teoria Queer: um aprendizado pelas diferenças. Belo Horizonte: Autêntica Editora, Universidade Federal de Ouro Preto, 2012.

ORTIZ, Fernando. Contrapunteo cubano del tabaco y el azúcar. La Habana: Editorial de las Ciencias Sociales, 1983.

RANCIÈRE, Jacques. O Mestre Ignorante. Belo Horizonte: Autêntica, 2002.

. Sobre políticas estéticas. Barcelona: Museo de Arte Contemporáneo, Universidad Autónoma de Barcelona, 2005. . The future of the image. London: Verso, 2007.

. Dissensus: On Politics and Aesthetics. London: Continuum, 2010.

RODRIGUEZ, Simón. O inventamos o erramos. Caracas: Monte Ávila Editores Latinoamericana CA, 2008.

SAWICKI, J. Disciplining Foucault: Feminism, Power and the Body. New York: Routledge, 1991. 
SULLIVAN, Graeme. Art Practice as Research: Inquiry in Visual Arts. LA: SAGE Publications, 2010.

TREND, David. Cultural Pedagogy: Art, Education, Politics. New York: Bergin \& Garvey, 1992.

VICTORIO FILHO, Aldo. Ensino de arte hoje: desafios, sentidos e sintonias. In Anais da 31 $1^{\text {a }}$ Reunião da Associação Nacional de Pós-graduação e Pesquisa em Educação, Caxambu, 2008.

WEINER, Eric. Making the Pedagogical (Re) Turn: Henry Giroux's Insurgent Cultural Pedagogy. JAC. Vol. 21 No. 2, p. 434- 451, Spring, 2001.

NOTAS

1. Neste artigo se entende a mutação como uma mudança irreversível das variáveis, por tanto mais profunda do que uma 'mudança ou transformação' em base ao pensamento de Fritjof Capra (2001).

2. Atkinson também chama-a de pedagogia contra o estado ou antipedagogia porque irrompe a normatização na educação com uma pedagogia que procura o assombro do novo, uma pedagogia do desconhecido.

3. Em concordância com o pensamento de Badiou, "novo" se entende aqui como uma forma de ver o mundo como se fosse pela primeira vez.

4. Autopoiese é o termo usado por Maturara e Varela para definir o sistema dos seres vivos como um sistema de autoprodução biológica.

5. Bishop (2012) identifica o surgimento na década de 1990 de um grande interesse dos artistas e dos curadores, em diferentes lugares do mundo, por uma arte socialmente engajada que recebe os nomes de "arte baseada na comunidade”, "experimentação comunitária”, "arte dialógica”, "arte litorânea", "arte intervencionista”, "arte colaborativa”, "arte contextual” e "arte participante”. Argumenta que "arte participante” ou Participatory Art envolve muitas pessoas à diferença de uma arte interativa que implica uma relação de um a um e por outra parte evita as ambiguidades do engajamento social que é inerente ao artista.

6. A noção de texto é compreendida aqui não como discurso linguístico, mas como "marca" em concordância com a desconstrução de Jacques Derrida. Para ele a noção de texto ou traço ou marca é pré-linguística, é a potência da linguagem onde há uma necessidade de relação com outra coisa ou com o outro. Para estas relações, pensa Derrida, a marca não requer de linguagem. Desta maneira o texto envolve tudo, o texto é o contexto.

7. Não deve-se ler aqui que as relações formais do texto não sejam importantes, uma coisa não elimina a outra, a intenção é dar maior ênfase sobre os aspectos interpretativos que se dão no contexto das relações entre o texto, o público e o artista.

8. Kitsch é uma palavra alemã que se refere a objetos ordinários copiados dos objetos da cultura erudita em material e qualidade inferior ao original. Termo usado por Clement Greenberg (Avant Garde and Kitsch, 1939) para designar a arte comercial, popular e folclórica e argumentar a sua inferioridade frente a superioridade da arte de vanguarda moderna.

9. Aqui relativo à Teoria Queer. 
10. A teoria estética kantiana do desinteresse argumenta que só a arte e a experiência estética conduzem a uma verdade pura. A política, a economia, as ciências sociais e até os sentimentos, por exemplo, se baseiam em ideologias e, portanto, mascaram a verdade. A arte despojada de ideologias, pelo contrário, é capaz de apresentar a verdade de uma maneira desinteressada. Esta pureza coloca o valor da arte na "forma pura" e não mais na representação da realidade, nas emoções ou na moral que mudam com o tempo, na diferença da forma que permanece efetiva através dos séculos. Esta ideia está também relacionada ao valor moderno de liberdade das regras acadêmicas que se estendem à liberdade das expectativas do público e à liberdade da função utilitária ou didática da arte. Desta maneira Kant divide as artes liberais do artesanato ou das artes mercantis.

Recebido em: 07/10/2013

Aceito em: 08/11/2013 


\section{BELIDSON DIAS \\ belidson@unb.br}

Professor do Instituto de Artes da UnB. Em 2013, organizou e publicou juntamente a Rita Irwin o livro Pesquisa Educacional Baseada em Arte: A/r/tografia, pela Editora da UFSM. Este Livro se origina de pesquisa do Grupo de Pesquisa TRANSVIAÇÕES: Visualidade e Educação da UnB realizada como professor visitante na University of British ColumbiaUBC, Canadá.

\section{TATIANA FERNANDEZ.}

tfernandezster@gmail.com

Professora do Instituto de Artes da UnB é Mestre e Especialista em arte, educação e tecnologias contemporâneas e doutoranda na Linha de Educação em Artes Visuais do PPG-ARTE do VIS/UnB. Membro do Grupo de Pesquisa TRANSVIAÇÕES: Visualidade e Educação da UnB cuja produção recente de artigos e capítulos está centrada na educação como arte e visualidade contemporânea e nas Investigações Baseadas nas Artes. Atualmente coordena o LIGO: Laboratório de Educação em Visualidade da UnB. 